Revista de
Economild
Contemporâned

\title{
NOVO DESENVOLVIMENTISMO - UM SEGUNDO MOMENTO DO ESTRUTURALISMO LATINO-AMERICANO
}

\author{
Luiz Carlos Bresser-Pereira ${ }^{a}$ \\ ${ }^{a}$ Professor emérito da Fundação Getúlio Vargas. São Paulo, SP, Brasil. ORCID: \\ https://orcid.org/0000-0001-8679-0557. \\ Recebido em 07 de fevereiro de 2019 \\ Aceito em 20 de agosto de 2019
}

RESUMO: A macroeconomia estruturalista do desenvolvimento e a correspondente estratégia nacional de desenvolvimento, o Novo Desenvolvimentismo que um grupo de economistas principalmente latino-americanos estão desenvolvendo, podem ser vistos como um segundo momento da economia estruturalista do desenvolvimento. Uma abordagem de impulso à demanda e modelos como o da doença holandesa, a crítica à "restrição estrangeira", a tendência da taxa de câmbio a se apreciar ciclicamente e o caráter cronicamente supervalorizado da taxa de câmbio nos países em desenvolvimento colocam pela primeira vez a taxa de câmbio no núcleo da economia do desenvolvimento.

PALAVRAS-CHAVE: taxa de câmbio; doença holandesa; restrição externa; poupança externa.

\section{CLASSIFICAÇÃO JEL: O11.}




\title{
NEW DEVELOPMENT - THE SECOND MOMENT OF LATIN AMERICAN STRUCTURALISM
}

\begin{abstract}
The structuralist development macroeconomics and the corresponding national development strategy, New Developmentalism that a group of mainly Latin American economists is developing may be seen as the second moment of the structuralist development economics. A demand-push approach and models like the one on the Dutch disease, on the critique of the "foreign constraint", on the tendency of the exchange rate to appreciate cyclically, and on the chronically overvalued character of the exchange rate in developing countries make put for the first time the exchange rate in the core of development economics.
\end{abstract}

KEYWORDS: exchange rate; Dutch disease; foreign constraint; foreign savings. 


\section{INTRODUÇÃO*}

Meu tema é o Novo Desenvolvimentismo e sua macroeconomia estruturalista do desenvolvimento. Venho desenvolvendo as ideias que aqui apresentarei desde 1999, quando deixei meu último cargo público e passei pela primeira vez em muitos anos a me dedicar exclusivamente à vida acadêmica e ao papel de intelectual público. Contando com a colaboração de um competente grupo de economistas pós-keynesianos e estruturalistas no Brasil e no exterior, creio ter estabelecido nesse período as bases para o Novo Desenvolvimentismo que, espero, possa ser considerada o segundo momento do estruturalismo latino-americano.

O primeiro momento foi comandado, nos anos 1950 e 1960, por Raúl Prebisch e Celso Furtado e concentrou sua atenção na justificação teórica da intervenção do Estado na economia e na necessidade de mudança estrutural - a industrialização - para que cada país lograsse superar a condição estrutural do subdesenvolvimento. Já a macroeconomia estruturalista do desenvolvimento foca sua atenção na demanda. Sem ignorar o lado da oferta, identifica a existência de uma tendência à sobreapreciação das moedas nacionais nos países em desenvolvimento que desligam as boas empresas do país da demanda existente tanto no plano nacional quanto no internacional. Por isso, deixam de estar presentes as oportunidades de investimentos necessárias que, se existentes, garantiriam o emprego de seus recursos humanos, materiais e institucionais e possibilitariam taxas elevadas de crescimento. Venho, dessa maneira, buscando definir uma nova abordagem teórica e uma estratégia nacional de desenvolvimento ou de competição internacional - o Novo Desenvolvimentismo - a partir da observação da antiga experiência latino-americana de desenvolvimento e da atual experiência dos países asiáticos dinâmicos.

Este conjunto de ideias foi sistematizado no livro "Globalização e Competição" (2010). Estava claro para mim, então, que esse livro longamente pensado e elaborado era a tentativa de construção de uma macroeconomia do desenvolvimento adaptada aos países de renda média como o Brasil - uma teoria que servia de fundamento para o Novo Desenvolvimentismo. Mas foi só depois de publicado o livro que me dei conta de que estavam ali lançadas as bases de uma macroeconomia estruturalista do desenvolvimento - estruturalista porque compartilha com os pioneiros do desenvolvimento econômico seu conceito do desenvolvimento econômico como mudança estrutural,

* Nota do Editor: Este texto foi originalmente apresentado na forma de discurso em conferência proferida pelo autor ao receber o título de Professor Honoris Causae na Escola de Economia da Universidade de Buenos Aires, em 18 de outubro de 2011. O texto original foi editado e reformatado para se adequar ao projeto gráfico e editorial da REC. 
porque adota o método histórico para pensar a economia; estruturalista, sob outro ângulo, de caráter pessoal, porque eu sempre me identifiquei com o pensamento estruturalista e o ensinei, porque tenho sido sempre um crítico da teoria econômica neoclássica, do novo institucionalismo e do modelo das expectativas racionais. Desde os anos 1950, quando comecei a estudar a economia brasileira, eu me declarei discípulo de Celso Furtado e de Raúl Prebisch, embora não tenha vivido no Chile, onde o estruturalismo econômico nasceu, e nem tenha tido relações profissionais com a CEPAL.

Eu comecei a escrever sobre economia nos anos 1960, quando publiquei, em 1968, “Desenvolvimento e Crise no Brasil". Escrevia então em um momento no qual a teoria estruturalista do desenvolvimento entrava em crise. Era uma teoria econômica baseada na crítica à lei das vantagens comparativas do comércio internacional. Seu fundamento político era nacionalista e desenvolvimentista, porque afirmava a necessidade de uma coalizão de classes desenvolvimentista para que o desenvolvimento econômico pudesse acontecer. Os países da periferia já estavam ou deveriam formar coalizões políticas envolvendo a burguesia nacional, os trabalhadores e a burocracia pública para poderem fazer avançar sua respectiva revolução nacional e industrial.

Entretanto, a revolução cubana em 1959, a radicalização política que se segue na América Latina e, em consequência, os golpes militares anticomunistas abriram espaço para que a teoria da dependência, que surge na segunda metade dos anos 1960, se tornasse dominante, substituindo a teoria cepalina. A interpretação da dependência, de caráter originalmente marxista, teve como ponto comum a tese da "impossibilidade" de existirem burguesias nacionais e pactos políticos nacionalistas em países periféricos, dependentes dos países ricos. Ou, em outras palavras, a tese da impossibilidade de se constituírem nações nos países subdesenvolvidos. Essa interpretação logo se dividiu em duas correntes. A original, a da superexploração imperialista, que teve em Andre Gunder Frank seu principal formulador, conservou seu caráter marxista e concluiu, de forma coerente, mas utópica, que a revolução socialista seria a condição do desenvolvimento econômico. Já a segunda, a teoria da dependência associada, que se tornou dominante na América Latina por muitos anos, considerou que não havia necessidade de nação e de nacionalismo nos países latino-americanos porque esses poderiam crescer se associando ao império e a suas empresas multinacionais que desde os anos 1950 investiam na produção de bens manufaturados na região.

A crise do estruturalismo latino-americano, que Albert Hirschman (1981) percebeu ainda em 1979, foi profunda. A teoria da dependência, que atacava no seu cerne político, na possibilidade da revolução nacional, "parecia" verdadeira. Como a burguesia industrial havia voltado a se unir em termos políticos com a burguesia agrícola e a financeira, estaria desmentida a tese de uma revolução burguesa e nacional nos países em desenvolvimento. Era o que afirmava tanto a teoria da dependência associada 
quanto a teoria da dependência e superexploração imperialista. Por outro lado, como essa burguesia, a partir de 1964 no Brasil e de 1967 na Argentina, unificada e associada aos militares e às empresas multinacionais, logrou no Brasil alcançar altas taxas de crescimento sem estabelecer restrições aos interesses externos, podia-se rejeitar a tese desenvolvimentista de que os países ricos eram contrários à industrialização na periferia do capitalismo. Não haveria, portanto, necessidade de nacionalismo para que os países em desenvolvimento prosperassem. O que seria necessário, diziam os progressistas dos anos 1970, era o retorno à democracia e a reforma do sistema econômico para torná-lo mais justo ou menos desigual.

Como entender o apoio dos intelectuais latino-americanos a essa interpretação e o consequente abandono dos projetos nacionais de desenvolvimento? Em primeiro lugar, ainda nos anos 1970, a tese da "impossibilidade" de revoluções nacionais e burguesas parecia verdadeira dada a adesão dos empresários industriais aos regimes militares. Segundo, porque a agenda da interpretação da dependência associada não era apenas negativa. Tinha dois objetivos políticos que eram muito caros aos cidadãos dos países em desenvolvimento: o retorno à democracia e a crítica à desigualdade. Esses objetivos garantiam às novas ideias legitimidade não obstante sua falta de conteúdo nacional. Terceiro, porque desde o final dos anos 1970 os Estados Unidos, que haviam apoiado os golpes militares na região, começavam a advogar democracia para os demais países. Quarto, porque, a partir da queda do muro de Berlim (1989), a hegemonia econômica neoclássica e a hegemonia política, neoliberal e globalista deslegitimavam qualquer proposta nacionalista e desenvolvimentista.

Em consequência dessa crise, a partir do início dos anos 1970 o Estruturalismo latino-americano, que era nacionalista e desenvolvimentista, foi imobilizado e cooptado pela tese da dependência associada. Assim, deixou de ter um discurso desenvolvimentista, e se concentrou nos problemas da heterogeneidade estrutural e da desigualdade. A CEPAL, que entre os anos 1940 e os 1960 havia sido um centro do pensamento estruturalista, aos poucos se transformou em uma agência internacional submetida à ortodoxia liberal, vivendo das glórias do passado. Não apenas deixou de orientar as políticas econômicas adotadas pelos países da região. Quando, na segunda metade dos anos 1980, o consenso de Washington se impôs como a nova verdade neoliberal, a CEPAL nada teve a oferecer como crítica e alternativa.

Entretanto, a partir dos anos 2000, as coisas começaram a mudar. Quando ficou evidente que o Neoliberalismo e a ortodoxia liberal haviam fracassado, surgiu a oportunidade da atualização e renovação do Estruturalismo; surgiu a oportunidade de uma crítica não apenas ao Liberalismo radical da ortodoxia, mas também à sua política de crescimento com endividamento ("poupança") externa e à correspondente política de juros altos e câmbio sobreapreciado. É sobre essa atualização ou esse aggiornamento que falarei hoje. 


\section{NOVO DESENVOLVIMENTISMO}

Nos anos 1950 os países latino-americanos não haviam ainda "completado" sua revolução nacional e industrial, ou seja, sua revolução capitalista, de forma que cabia ao Estado um papel decisivo de promover a acumulação original através de mecanismos de poupança forçada. Hoje, países como a Argentina, o Brasil e o México já contam com uma grande classe de empresários, com uma classe profissional cada vez mais significativa e com uma classe operária razoavelmente capacitada, de forma que os desafios econômicos que enfrentam são outros. Desafios que podem ser mais bem compreendidos a partir do Novo Desenvolvimentismo. Entretanto, para que isso ocorra, para que o estruturalismo latino-americano viva um segundo momento, será necessário que, de um lado, as políticas econômicas dos países latino-americanos se tornem mais desenvolvimentistas e, de outro, que seus economistas estruturalistas passem a contribuir ativamente para a formulação e justificação empírica do Novo Desenvolvimentismo e de sua macroeconomia estruturalista. Em termos de políticas desenvolvimentistas, houve um grande avanço nesta década em vários países, principalmente na Argentina. Em termos teóricos, são notáveis, além da contribuição de meus associados brasileiros, a contribuição dada pelos economistas sediados no Centro de Estudos Educação e Sociedade (CEDES), capitaneados por Roberto Frenkel, e pelos economistas do Projeto Fenix, da Universidade de Buenos Aires, liderado por Aldo Ferrer. Mas mesmo no Brasil e na Argentina há muito a fazer tanto no plano teórico e empírico quanto no plano das políticas econômicas para tornar o Novo Desenvolvimentismo a teoria econômica orientadora do Desenvolvimentismo como o estruturalismo foi no pós-guerra.

Não obstante o desenvolvimento econômico dependa também de fatores do lado da oferta (educação, progresso técnico e científico, investimentos na infraestrutura, boas instituições), a macroeconomia estruturalista do desenvolvimento afirma que seu ponto de estrangulamento está no lado da demanda. O desenvolvimento econômico depende de uma taxa de investimento elevada, que depende da existência de oportunidades de investimentos lucrativos para as empresas, que, por sua vez, dependem da existência de demanda interna e demanda externa. Entretanto, essas duas demandas tendem a ser insuficientes nos países em desenvolvimento devido a duas tendências estruturais: a tendência de os salários crescerem menos do que a produtividade (que deprime a demanda interna) e a tendência à sobrevalorização cíclica da taxa de câmbio, que coloca toda a demanda externa fora do alcance das empresas nacionais mesmo que elas sejam eficientes ou competentes.

A primeira tendência decorre da oferta ilimitada de mão de obra existente nos países em desenvolvimento. A grande vantagem desses países em relação aos países 
ricos está em sua mão de obra barata, mas, como ela é abundante, tende a ser mal remunerada, o que cria um problema de insuficiência de mercado interno. Conforme Celso Furtado sempre salientou, a política de desenvolvimento deve estar sempre preocupada em enfrentar esse problema, não apenas por uma questão de justiça social, mas porque um desenvolvimento sadio e sustentado não se coaduna com o aumento da desigualdade em países nos quais essa desigualdade já é muito grande. Em países de renda média como o Brasil e a Argentina, essa tendência perde força na medida em que deixa de haver uma oferta ilimitada de mão de obra.

A segunda tendência - a tendência à sobrevalorização cíclica da taxa de câmbio - é nova na literatura econômica. É uma crítica tanto à teoria neoclássica ou ortodoxa, que afirma que a taxa de câmbio flutua suavemente em torno da taxa que equilibra intertemporalmente a conta corrente do país, quanto à teoria keynesiana que afirma que ela flutua de forma volátil em torno desse mesmo equilíbrio. Ao invés, o que afirma a macroeconomia estruturalista do desenvolvimento é que, nos países em desenvolvimento, a taxa de câmbio não é controlada pelo mercado, mas pelas crises cíclicas de balanço de pagamentos. O ciclo começa com uma crise de balanço de pagamentos, ou seja, com a súbita suspensão da rolagem da dívida externa do país em moeda estrangeira pelos credores externos e, em consequência, a forte desvalorização da moeda local. Em seguida, depois do inevitável ajuste que o país é obrigado a fazer, a taxa de câmbio volta a se apreciar gradualmente, puxada pela doença holandesa e, depois de algum tempo, por déficits em conta corrente causados pela política de crescimento com poupança externa e pela tentativa de segurar a inflação com o câmbio. A dívida externa volta a aumentar, e, afinal, de repente, os credores externos perdem a confiança, suspendem a rolagem da dívida externa, e acontece nova crise de balanço de pagamentos ou novo sudden stop que leva a moeda nacional a se desvalorizar violentamente.

Há quatro causas fundamentais para essa tendência, três das quais associadas à prática de altas taxas de juro: (i) a doença holandesa, que atinge quase todos os países em desenvolvimento; (ii) as altas taxas de juro que atraem capitais e alimentam o "fetiche da poupança externa" (a crença de que os países devem incorrer em déficits em conta corrente para crescer); (iii) as altas taxas de juro e a consequente apreciação da moeda nacional para reduzir a inflação; e (iv) o "populismo cambial", novamente as altas taxas de juros para atrair capitais, apreciar a moeda nacional e, assim, aumentar artificialmente os salários reais e lograr reeleição. No quadro da macroeconomia estruturalista do desenvolvimento, o modelo da doença holandesa explica porque a taxa de câmbio de mercado tende para o equilíbrio corrente que é um equilíbrio sobreapreciado e não viabiliza indústrias utilizando tecnologia no estado da arte mundial; o modelo da taxa de substituição da poupança interna pela externa mostra quão equivocado é o fetiche da poupança externa; as duas últimas causas da tendência à sobreapreciação cíclica da taxa de câmbio não exigem explicação adicional àquela presente em sua enunciação. 
A doença holandesa caracteriza-se pela existência de duas taxas de câmbio de equilíbrio, podendo ser definida como uma sobreapreciação permanente da taxa de câmbio causada pelas rendas ricardianas (Ricardian rents) e por booms de commodities derivados de recursos naturais abundantes. Quando há doença holandesa em um país observamos dois equilíbrios; o equilíbrio corrente, que torna viável a exportação de commodities e equilibra a sua conta-corrente, e o equilíbrio industrial que corresponde à taxa de câmbio substancialmente mais desvalorizada que torna viável economicamente a produção de bens comercializáveis internacionalmente que utilizam tecnologia no estado da arte mundial - basicamente os bens manufaturados.

A diferença entre essas duas taxas indica a gravidade da doença holandesa. Em países produtores de petróleo essa diferença é geralmente muito maior do que em países produtores de commodities agrícolas. Se, por exemplo, a taxa de câmbio de equilíbrio corrente no país exportador de petróleo for de \#2 moedas do país por dólar e a taxa de câmbio de equilíbrio industrial for de \#10 moedas do país por dólar, esse país terá uma doença muito mais grave do que outro país, neste caso produtor de soja, cuja taxa de câmbio de equilíbrio corrente for igualmente de \#2 moedas do país por dólar, mas sua taxa de câmbio de equilíbrio industrial for de \#3 moedas por dólar. No primeiro país, a gravidade da doença holandesa (que pode ser definida como a diferença entre as duas taxas dividida pela taxa de equilíbrio industrial) será de $80 \%$, enquanto no segundo país será de 33,3\%. No primeiro país investimentos em outras indústrias de bens comercializáveis serão completamente inviáveis se o país não neutralizar a doença holandesa; no segundo caso algumas indústrias mais eficientes e com alguma proteção tarifária poderão sobreviver no mercado interno, mas não poderão exportar. O primeiro caso é típico de países como a Venezuela e a Arábia Saudita e o segundo, de países como o Brasil desde que fez sua abertura comercial e financeira (1990-91) e deixou de administrar sua taxa de câmbio.

O Gráfico 1 torna mais fácil compreender o ciclo de sobreapreciação e crise dos países exportadores de commodities e, portanto, sujeitos à doença holandesa. Nele temos as curvas de equilíbrio corrente e de equilíbrio industrial e a taxa de câmbio real que varia de acordo com a tendência à sobreapreciação cíclica da taxa de câmbio. $\mathrm{O}$ equilíbrio corrente varia principalmente de acordo com o preço das commodities exportadas, enquanto o equilíbrio industrial varia de acordo com a variação no custo de produção industrial do país em comparação com o custo industrial dos seus países concorrentes. A taxa de câmbio real, ao invés de flutuar de maneira suave como supõe a teoria ortodoxa, ou da maneira volátil suposta pelos keynesianos, varia de acordo com um ciclo cambial que começa e termina com uma crise financeira. Como vemos no gráfico, o ciclo começa com uma crise de balanço de pagamentos e uma violenta depreciação, que leva a taxa de câmbio acima (mais depreciada) do equilíbrio indus- 
trial. Em seguida, a doença holandesa "puxa" a taxa de câmbio para o equilíbrio corrente - o nível com a qual essa grave falha de mercado é compatível. Mas, devido à política de altos juros, que atraem capitais, a taxa de câmbio continua a se apreciar e mergulha na área do déficit em conta corrente. Permanece nessa área durante alguns anos, acumulando dívida externa, até que os credores internacionais percam confiança e nova crise se desencadeie encerrando o ciclo.

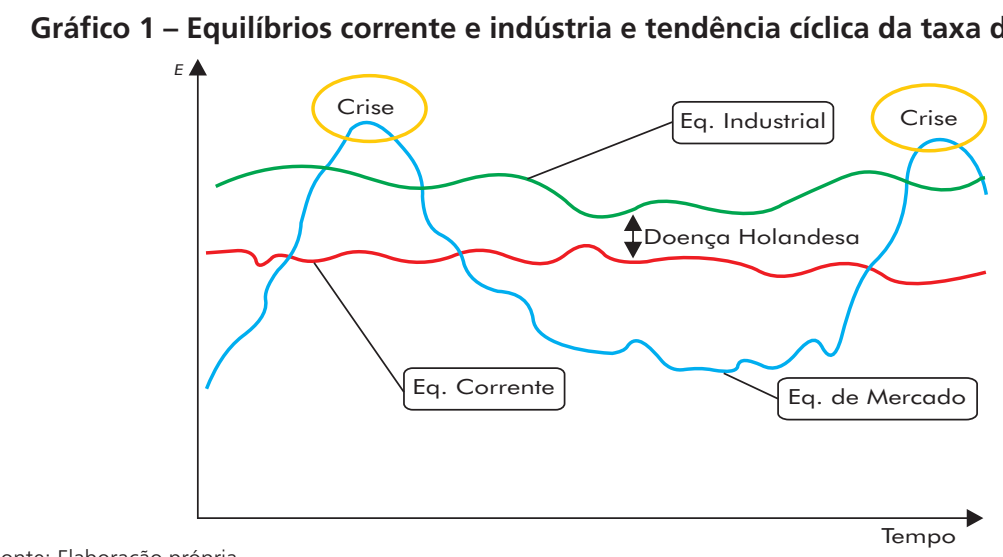

Fonte: Elaboração própria.

\section{NÃO À TESE DA “RESTRIÇÃO EXTERNA"}

Para entender por que a taxa de câmbio continua a se apreciar, entra na área de deficit em conta corrente e termina por levar o país à crise de balança de pagamentos, é preciso considerar as entradas de capitais. São entradas excessivas das quais o país de renda média não tem necessidade, mas que, não obstante, entram no país na medida em que os economistas e as elites locais se deixam persuadir pelos países ricos de que essas entradas seriam necessárias.

Para entender esse fato, devemos, primeiro, supor que o país tenha doença holandesa, originária seja de recursos naturais abundante e baratos, seja de mão de obra barata acoplada por um "leque salarial" muito maior do que o existente nos países ricos. ${ }^{1}$ A doença pode ser grave ou moderada, mas nos dois casos sua neutralização implicará na imposição de um imposto de exportação igual à diferença em moeda local entre o equilíbrio industrial e o equilíbrio corrente. Ora, esse deslocamento impli-

\footnotetext{
1 Leque salarial é a diferença entre o salário médio do engenheiro de fábrica e o salário médio do peão.
} 
cará necessariamente um superavit em conta corrente, já que por definição a taxa de câmbio situada no equilíbrio industrial é mais desvalorizada do que a taxa que equilibra intertemporalmente a conta corrente de um país.

Mas o país em desenvolvimento não "precisaria” de capitais externos para crescer? É isso que sempre nos disseram economistas de todas as tendências, é isso que interessa muito aos países ricos, é por isso que eles afirmam que há uma "restrição externa" a ser sanada. Mas, pelo menos em relação aos países de renda média, essa tese - a política de crescimento com poupança externa é definitivamente falsa. Para entender isso desenvolvi a partir de 2002 uma crítica teórica simples, mas a meu definitiva desses dois conceitos correlatos: o de restrição externa e o de crescimento com poupança externa.

A tese da restrição externa é autoevidente para os economistas ortodoxos, enquanto para os economistas estruturalistas e os keynesianos ela está baseada nas duas elasticidades-renda perversas. A elasticidade-renda das importações dos países em desenvolvimento que é maior do que um porque eles importam principalmente bens manufaturados, e a elasticidade-renda das importações dos países ricos que é menor do que um porque eles importam principalmente as commodities produzidas pelos primeiros. Definida a "restrição externa”, sua superação deveria ser feita através do recurso a capitais externos que seriam "estruturalmente" necessários. O conceito de restrição externa está, portanto, associado ao de financiamento externo. É claro que podemos pensar em uma restrição externa que não fosse associada ao endividamento.

O pressuposto dos que defendem o conceito de poupança externa e de crescimento com deficit em conta corrente é o de que a poupança externa se soma à poupança interna. Isso parece verdade, mas é mera aparência: é tão verdade quanto é verdade que a terra é plana. A política de crescimento com poupança externa proposta pelos países ricos aos países em desenvolvimento e aceita por estes afirma que: (i) os países em desenvolvimento devem incorrer em deficit em conta corrente e financiá-los com entradas de capitais "para aumentar a poupança total" e (ii) que podem e devem aumentar juros para atrair capitais, apreciar a taxa de câmbio e, assim, atingir uma meta de inflação. As duas estratégias implicam atração de capitais externos. A primeira é o incentivo à busca de financiamento externo e a deliberada incursão em deficit em conta corrente (que, na literatura econômica, são chamados de forma eufemística de "poupança externa”) para, assim, aumentar a taxa de poupança do país e, assim, sua taxa de investimento sobre o PIB; a segunda, uma clássica distorção do regime de metas de inflação. Entretanto, conforme demonstra o modelo que desenvolvi de substituição da poupança interna pela externa, as entradas de capitais não causam, principalmente, o aumento da poupança total e do investimento e, sim, o aumento do consumo e a diminuição da poupança interna, ocorrendo, assim, uma elevada taxa de substitui- 
ção da poupança interna pela externa. Os deficit em conta corrente almejados pela política econômica exigem entradas de capitais para financiá-los que apreciam a moeda local. Em consequência, de um lado, os salários aumentam artificialmente, o consumo também aumenta artificialmente (dada a existência de uma elevada propensão marginal a consumir), a poupança interna cai e a poupança externa limita-se a substituir a interna. De outro lado, em termos mais keynesianos, a apreciação da moeda nacional, depois de um rápido período de estímulo ao investimento devido ao barateamento dos equipamentos importados, cai porque desaparecem as oportunidades de investimentos voltados para exportação e porque bens importados passam a inundar o mercado interno. O resultado, tanto de acordo com o primeiro quanto com o segundo raciocínio, é pouco ou nenhum aumento da taxa de investimento e de poupança total do país; ao invés, aumentam o consumo e a dívida externa. Só em momentos excepcionais, quando o país já está crescendo aceleradamente e a propensão marginal a consumir se torna pequena, uma política de crescimento com poupança externa é benéfica para o país. Na maioria das vezes, mesmo que se trate de investimento em capital físico, beneficia-se principalmente o investidor externo que recebe altos juros ou tem acesso sem reciprocidade ao mercado interno do país.

Portanto, geralmente a poupança externa não se soma à interna, mas em grande parte a substitui. Por que não se percebeu isto antes? Porque percebê-lo não interessa aos países ricos, que estão interessados em fazer empréstimos a juros altos para os países em desenvolvimento ou então em ocupar seu mercado interno sem reciprocidade através dos investimentos e das vendas de suas empresas multinacionais. ${ }^{2}$ Para justificar esse financiamento em moeda do seu país, os países ricos e seus economistas precisam convencer o país em desenvolvimento de que ele maximizará seu crescimento se recorrer à poupança externa, que deverá ter seu deficit em conta corrente o mais compatível possível com a não eclosão de uma crise de balanço de pagamentos, que, afinal, é a condição normal de todo país em desenvolvimento ser frágil financeiramente porque precisaria da poupança externa.

Isto não significa que todo investimento de empresas multinacionais seja prejudicial ao país. Quando o país já tem superavit em conta corrente e as entradas de capitais que o acompanham não vêm para financiar o deficit em conta corrente e apreciar o câmbio, mas para trazer tecnologia, não há nada a objetar. Este é o caso da China, que

\footnotetext{
2 Entre os países ricos os investimentos diretos implicam reciprocidade, porque eles tanto cedem seu mercado interno para as multinacionais de outros países, quanto estes cedem para as empresas multinacionais do primeiro seus mercados. Não é esse o caso dos países em desenvolvimento. Só recentemente eles começaram a ter empresas multinacionais.
} 
há muitos anos apresenta superavit em conta corrente, mas admite a entrada de capitais estrangeiros desde que tragam tecnologia. A China não precisa dos capitas, porque cresce com despoupança externa; a entrada de capitais não preenche rombo externo, mas apenas aumenta as reservas internacionais do país.

A rejeição ao financiamento externo também não significa que um sistema financeiro nacional bem desenvolvido deixe de ser considerado fundamental para o desenvolvimento. $\mathrm{O}$ papel desse sistema é financiar o investimento e, assim, viabilizar o aumento da poupança. Mas o financiamento é interno, é concedido pelo sistema financeiro nacional que faz empréstimos em moeda do país às empresas que estão investindo e, dessa forma, não aprecia a taxa de câmbio como acontece quando o empréstimo externo é feito em divisa forte.

Em síntese, nos países de renda média como o Brasil ou a Argentina não existe "falta" de capitais. O que falta são oportunidades de investimentos lucrativos. Quando a taxa de câmbio se torna competitiva (no equilíbrio industrial), essas oportunidades passam a existir e, em havendo crédito (coisa que existe no Brasil graças ao BNDES, ao mercado de ações e, crescentemente, graças aos grandes bancos brasileiros), os empresários inovadores obtêm esse crédito, investem e, em consequência, keynesianamente, a taxa de poupança cresce. Uma taxa de câmbio equilibrada ou competitiva é essencial para o desenvolvimento econômico porque ela coloca ao alcance das empresas nacionais que utilizam tecnologia no estado da arte mundial toda a demanda externa mundial. Dada a vantagem de ter uma mão de obra barata, os países em desenvolvimento que mantiverem sua taxa de câmbio estável e no equilíbrio industrial, que é o verdadeiro câmbio de equilíbrio do país, crescerão de forma acelerada realizando o catching up. Mas para isso precisam adotar a política de crescimento com poupança interna e neutralizar a doença holandesa.

\section{TAXA DE CÂMBIO NO CENTRO DA TEORIA}

Os modelos da macroeconomia estruturalista colocam, creio que pela primeira vez, a taxa de câmbio no centro da teoria do desenvolvimento. As escolas de pensamento anteriores, inclusive a keynesiana e a estruturalista, não haviam adotado essa posição porque supunham que a taxa de câmbio se desequilibrasse apenas no curto prazo; que, ao contrário do que afirmam os economistas neoclássicos, a taxa de câmbio apresenta grandes variações, é muito volátil. No momento, porém, em que afirmei e demonstrei teoricamente que a taxa de câmbio apresenta uma tendência cíclica à sobreapreciação, de forma que as empresas voltadas para a exportação não podem contar com o pressuposto de que ela permanecerá em relativo equilíbrio - precisam supor que ela estará 
geralmente sobreapreciada, cronicamente sobreapreciada - a taxa de câmbio se transforma em uma variável fundamental do desenvolvimento. Venho elaborando o modelo teórico que coloca a taxa de câmbio no centro da teoria do desenvolvimento desde 2002. Nos últimos anos houve um aumento substancial do número de papers empíricos relacionando câmbio com desenvolvimento: Ofair Razin e Suzan M. Collins (1997), Heiner Flassbeck (2001), Paulo Gala (2008), Dani Rodrik (2007), Barry Eichengreen (2008). Mas esses trabalhos não apresentam uma teoria que explique a relação entre a taxa de câmbio e o desenvolvimento econômico. Essa relação teórica está principalmente em Bresser-Pereira (2002, 2008, 2009), Bresser-Pereira e Nakano (2002, 2003), Bresser-Pereira e Gala (2007), Gala (2008). Embora em "Globalização e Competição" (BRESSER-PEREIRA, 2009) $)^{3}$ eu não afirme que o livro estabelece as bases de uma macroeconomia estruturalista do desenvolvimento ou de uma macroeconomia novo-desenvolvimentista (eu cheguei a essa denominação um pouco depois de ter sido ele publicado), esse livro contém quase todas as ideias resumidas no presente trabalho.

Uma taxa de câmbio competitiva é fundamental para o desenvolvimento econômico porque ela funciona como uma espécie de interruptor de luz que "liga" ou "desliga" as empresas tecnológica e administrativamente competentes à demanda mundial. Uma taxa de câmbio competitiva estimula os investimentos orientados para a exportação e aumenta correspondentemente a poupança interna. Uma taxa de câmbio competitiva é aquela que se situa no "equilíbrio industrial", ou seja, que corresponde à taxa de câmbio necessária para que empresas que utilizem tecnologia no estado da arte mundial sejam internacionalmente competitivas. O que é uma taxa de câmbio competitiva? Não é uma taxa de câmbio "relativamente desvalorizada" como pensei durante um certo tempo, mas a taxa de câmbio de "equilíbrio" industrial que defini ao desenvolver o modelo de doença holandesa baseado em duas taxas de câmbio de equilíbrio. Por que ela tende a se sobreapreciar? Porque, primeiro, a doença holandesa a puxa do equilíbrio industrial para o corrente; segundo, porque as entradas excessivas de capital causadas principalmente pela equivocada política de crescimento com poupança externa - promovida através da elevação da taxa de juros para atrair capitais e através do aumento irresponsável das despesas do Estado -, e também devido ao uso de âncoras para combater a inflação, à política de elevação da taxa de juros para superar a "repressão financeira" e ao populismo cambial apreciam ainda mais a moeda nacional, levando a taxa de câmbio para baixo do equilíbrio corrente, na área do deficit em conta corrente.

\footnotetext{
3 Cito a versão em francês porque foi ela a primeira a ser publicada. Em seguida o livro foi publicado sucessivamente em português, inglês e francês.
} 
A tendência à sobrevalorização cíclica da taxa de câmbio existente nos países em desenvolvimento não varia, portanto, em torno de uma taxa de equilíbrio, como supõe a teoria econômica - nem flutua de forma bem comportada, como supõe a teoria convencional, nem de maneira volátil, como afirmam os economistas keynesianos. Não é o mercado, mas são as crises de balanço de pagamentos que determinam seus ciclos. Não havendo qualquer política de administração da taxa de câmbio que neutralize essa tendência, o ciclo começará por uma crise que depreciará de forma abrupta e violenta a taxa de câmbio. Esta que, quando se iniciou o ciclo, estava abaixo do "equilíbrio corrente" (que equilibra intertemporalmente a conta corrente do país), deprecia-se violentamente para, em seguida, passar a se apreciar puxada por dois fatores estruturais: primeiro, a doença holandesa a leva até o nível de equilíbrio corrente, e, em seguida, os fluxos de capitais atraídos pelas taxas de lucro e de juros, que tendem a ser mais elevadas, continuam a apreciá-la levando ao deficit em conta corrente. Essa atração estrutural, somada a políticas equivocadas que não são estruturais, mas são recorrentes, continuarão a apreciar a taxa de câmbio até que nova crise de balanço de pagamentos interrompa o processo. Na medida em que as autoridades do país praticam essas políticas ao mesmo tempo em que continuam a se negar a administrar a taxa de câmbio, o país entrará em deficit em conta corrente, ficará endividado e gradualmente perderá a confiança dos credores, que, em certo momento, determinam o sudden stop, ou seja, deixam de rolar a dívida externa do país e este entra em crise de balanço de pagamentos que, novamente, deprecia a moeda nacional.

Uma taxa de câmbio competitiva é fundamental para o desenvolvimento econômico porque coloca todo o mercado externo à disposição das empresas nacionais realmente competentes do ponto de vista administrativo e tecnológico. Dado o progresso técnico em curso (a variável básica do crescimento do lado da oferta), o desenvolvimento econômico é função da taxa de investimento. Ora, uma taxa de câmbio competitiva estimula os investimentos orientados para a exportação e aumenta correspondentemente a poupança interna. Estimula os investimentos das empresas que usam tecnologia no estado da arte mundial, as quais não seriam competitivas no plano internacional se a taxa de câmbio fosse cronicamente sobreapreciada. Quando o nível da taxa de câmbio corresponde ao "equilíbrio industrial", toda a imensa demanda externa é aberta para as empresas realmente competentes que usem a melhor tecnologia disponível no mundo. Uma taxa de câmbio em um país que não sofra da doença holandesa (são raros os países em que isso ocorre se utilizarmos o conceito amplo de doença holandesa) é a taxa câmbio que equilibra intertemporalmente a conta corrente: a taxa de câmbio de "equilíbrio corrente"; nos demais países, é a taxa que viabiliza setores econômicos comercializáveis produzindo bens e serviços com utilização da tecnologia mais avançada no mundo, é a taxa de equilíbrio industrial. 


\section{NOVO DESENVOLVIMENTO E ORTODOXIA LIBERAL}

No quadro da globalização os países competem entre si. Por isso, precisam de uma teoria e uma estratégia nacional de desenvolvimento. O Novo Desenvolvimentismo é o nome dessa teoria e dessa estratégia. Além de defender políticas do lado da oferta como a educação, o apoio à ciência e à tecnologia, e a política industrial, a grande novidade econômica está em definir no plano teórico o papel da taxa de juros e a da taxa de câmbio no desenvolvimento, mostrar que esses dois preços macroeconômicos geralmente estão fora do lugar e defender uma política macroeconômica ativa que os ponha no lugar certo. Para a perspectiva neoliberal basta que o Estado garanta o bom funcionamento do mercado; para o novo desenvolvimentista o Estado não tem mais o papel de Estado produtor que tinha no Estruturalismo, mas tem entre seus papéis econômicos o de evitar a armadilha macroeconômica dos juros altos e do câmbio apreciado.

Tanto a teoria econômica neoclássica e sua ortodoxia liberal quanto o Novo Desenvolvimentismo são responsáveis no plano fiscal, mas a primeira se limita a assegurar um superavit primário que mantenha a relação dívida/PIB constante, enquanto que o Novo Desenvolvimentismo quer, além disso, uma poupança pública que permita ao Estado investir complementarmente ao setor privado.

Em termos cambiais, a ortodoxia liberal é pateticamente populista e contraditória na medida em que defende deficit em conta corrente. Se, como o Novo Desenvolvimentismo, é contra os deficit públicos elevados, porque isso significa que o Estado gasta mais do que arrecada, por que defende os deficit em conta corrente que significam que o Estado-nação gasta mais que arrecada? Embora o economista convencional não goste de confessá-lo, ele está advogando a favor de dois deficit - o deficit em conta corrente e o deficit público. Atende, assim, ao modelo ou à teoria dos deficit gêmeos: quando temos um deficit, tendemos a ter o outro. Mas inverte a relação usualmente suposta nesse modelo: não é o deficit público desejado pelo político populista que causa o deficit em conta corrente, mas é o deficit em conta corrente desejado pelo economista ortodoxo que causa ou requer o deficit público.

Já o Novo Desenvolvimentismo defende uma política de crescimento ou poupança interna e tem propostas claras para neutralizar a doença holandesa. Na verdade, para um país que tem doença holandesa, os deficit em conta corrente e os deficit públicos significam irresponsabilidade cambial e pouca seriedade fiscal. Um país que tem doença holandesa pode e deve ter superavit em conta corrente. Se o país consegue neutralizar sua doença holandesa, isso significa que deslocou sua taxa de câmbio do equilíbrio corrente para o equilíbrio industrial e, portanto, que passou a ter superavit em conta corrente. A lógica do modelo é claríssima a respeito.

Além disso, esse país que neutraliza sua doença holandesa pode ter superavit fiscal e deve, pelo menos, praticar deficit público zero. Para entender isso sem recorrer ao 
raciocínio inverso dos deficit gêmeos, é preciso entender como é que se neutraliza a doença holandesa. Isso se faz essencialmente (como faz hoje a Noruega em relação a seu petróleo, o Chile em relação ao cobre, e a Argentina em relação à soja) impondo um imposto ou retenção sobre a exportação desse bem correspondente à diferença entre o equilíbrio industrial e o equilíbrio corrente. Ao se estabelecer essa retenção, a oferta do bem em relação à taxa de câmbio se deslocará para cima, o que causará a depreciação da moeda nacional e resultará na mudança do equilíbrio corrente do país, que se equalizará ao equilíbrio industrial. Esta depreciação ocorrerá porque, a partir do imposto, o produtor da commodity que origina a doença holandesa não está mais disposto a oferecer seu produto pela taxa de câmbio anterior ao imposto; condiciona sua produção a uma depreciação que compense o imposto pago. Voltando ao exemplo do país exportador de soja, se o governo impõe uma retenção de \#1 moeda nacional por dólar exportado de soja, os produtores de soja só continuarão a oferecer a soja (ou seja, a produzi-la) se a taxa de câmbio mudar de \#2 para \#3 moedas nacionais por dólar, e é para esse nível que o mercado funcionando livremente levará a taxa de câmbio. Há, certamente, um processo de transição que precisa ser cuidado pelo governo, mas, afinal, não é o produtor de soja que paga o imposto; ele fica exatamente na mesma posição, com a mesma rentabilidade: antes do imposto recebia \#2 moedas por dólar exportado, depois recebe \#3 moedas por dólar exportado, mas paga uma moeda de retenção. Quem paga o imposto é todo o povo do país, porque com a desvalorização os preços dos bens comercializáveis sobem e os salários reais caem. Mas, em seguida, a economia passa a crescer aceleradamente e esse prejuízo é em pouco tempo compensado.

$\mathrm{O}$ que deve fazer o governo com a receita do imposto? Em princípio deve fazer o que faz a Noruega. Ao invés de gastá-lo, o investe em um fundo soberano. Supondo-se que o orçamento do Estado, desconsiderado o imposto, está equilibrado, o imposto de exportação deverá constituir superavit público. Se, mais realisticamente, supusermos que, sem considerar a doença holandesa e o imposto que a neutraliza, é razoável que o país incorra em um deficit público moderado (que mantém constante a dívida pública do país em relação ao $\mathrm{PIB}$ ), a adição do imposto de exportação à receita do Estado deverá reduzir esse deficit público para próximo de zero. Se o Estado decidir gastar os recursos do imposto, deverá e poderá fazê-lo moderadamente de forma que não ficará longe do deficit público zero.

Quanto à política monetária, o único objetivo da ortodoxia liberal é controlar a inflação, enquanto o Novo Desenvolvimentismo quer, adicionalmente, manter a taxa de câmbio competitiva, no nível do equilíbrio industrial, e evitar crises financeiras que, nos países em desenvolvimento, são crise de balança de pagamentos.

Finalmente, na medida em que exista a tendência de os salários crescerem menos do que a produtividade, é necessária uma política para compensá-la. O Novo Desen- 
volvimentismo defende políticas de salário e de renda nessa direção, enquanto a ortodoxia liberal está apenas preocupada em "flexibilizar" o mercado de trabalho, ou seja, baixar os salários.

Em síntese, o Novo Desenvolvimentismo é mais seguro e responsável do que a ortodoxia liberal. A ortodoxia liberal propõe deficit em conta corrente (poupança externa) e, apesar de toda a sua retórica austera que leva o economista convencional a resolver todos os problemas com a diminuição do gasto público, está também baseada na manutenção do deficit público, quando o correto é zerar esse deficit quando o país tem doença holandesa. Ao invés disso, a ortodoxia liberal propõe taxa de juros real alta "para combater a inflação". Como, porém, o grande devedor é o Estado, a ortodoxia liberal sabe que esses juros impactarão sobre o deficit público, de forma que, coerentemente, e para manter o grau de endividamento estável (afinal ela não pode colocar em risco a dívida pública, que é a galinha dos ovos de ouro para os rentistas), ela propõe superavit primário inferior ao total de juros pagos pelo Estado, o que significa deficit público. No Brasil, enquanto o total de juros pagos pelo Estado tem girado em torno de $7 \%$, o superavit primário ficou em $4 \%$, de forma que continua a haver um deficit público de $3 \%$ do PIB.

Mas falta responder a uma pergunta básica: através desta estratégia de crescimento com poupança interna e neutralização da doença holandesa, como o país conseguirá aumentar sua taxa de investimento e de poupança, já que o Novo Desenvolvimentismo rejeita a proposta equivocada de tentar adicionar à poupança interna à externa, porque seu resultado é antes aumento do consumo e da dívida externa do que do investimento? A resposta está em administrar a taxa de câmbio, ainda que no quadro de um câmbio flutuante, para que ela não se aprecie, seja competitiva e permaneça em torno do equilíbrio industrial. Para isso, será necessário neutralizar a doença holandesa e rejeitar o fetiche da poupança externa ou, em outras palavras, buscar crescer da única forma possível, com base na poupança interna. Graças a uma taxa de câmbio competitiva as oportunidades de investimento aumentarão imediatamente para as empresas eficientes. Aumentarão em relação ao mercado externo porque toda a demanda externa ficará ao alcance dessas empresas, e em relação ao mercado interno porque diminuirá para elas a competição dos bens importados. Ao aumentar a taxa de investimento, aumentará a renda, e, como demonstrou Keynes, aumentará a taxa de poupança. Não se aumenta, portanto, a taxa de poupança do país recorrendo a uma ilusória poupança externa, mas garantindo demanda para as empresas e investindo. Para que as empresas invistam basta que, em termos de Schumpeter, o sistema financeiro nacional disponibilize crédito para as empresas inovadoras; dessa forma estarão inovando, obtendo lucros e promovendo o desenvolvimento econômico do país. 
Além de desempenhar o papel indutor de oportunidades de investimento, o Estado deve, de um lado, aumentar a eficiência de seu gasto na área dos serviços sociais e culturais e, assim, obter recurso para, sem aumentar a carga tributária, poder aumentar seus próprios investimentos, sem, naturalmente, concorrer com os investimentos privados, mas complementando-os e incentivando-os. Se, por exemplo, o objetivo no médio prazo no Brasil for aumentar a taxa de investimento de $18 \%$ para $25 \%$ do PIB, o Estado deverá aumentar seu investimento dos atuais 2\% para cerca de 5\% (cerca de $20 \%$ do total), ficando o setor privado responsável por investimentos equivalentes a $20 \%$ do PIB. Enquanto para o velho desenvolvimentismo o Estado devia ser também produtor, porque o setor privado não tinha capacidade de investir, hoje, no quadro do Novo Desenvolvimentismo, em um país que já realizou sua revolução capitalista, o papel do Estado na área econômica deve ser apenas estratégico ou indutor.

Em síntese, o Novo Desenvolvimentismo defende superavit em conta corrente e deficit público em torno de zero, porque a neutralização da doença holandesa leva a economia do país nessa direção, e rejeita a proposta dos países ricos de que os países em desenvolvimento cresçam com poupança externa, porque essa tese não se sustenta nem lógica nem empiricamente (já há muitas pesquisas comprovando esse fato). Através da neutralização da doença holandesa e da política de crescimento com poupança interna, o país aumenta sua taxa de investimento e de poupança e cresce aceleradamente com estabilidade de preços e sem ficar sujeito a crises cíclicas de balanço de pagamentos. É, portanto, uma estratégia muito mais segura e responsável do que a ortodoxia liberal que defende deficit em conta corrente e aceita deficit público para financiar juros altos pagos pelo Estado.

\section{5. É POSSÍVEL MUDAR A POLÍTICA MACROECONÔMICA?}

Para tornar o Novo Desenvolvimentismo a política econômica do país é fundamental convencer sua sociedade civil - ou seja, a sociedade politicamente organizada formada por empresários, classes médias intelectuais, organizações corporativas e organizações de advocacia política. A rigor seria preciso convencer o povo - a massa dos eleitores -, mas nas democracias imperfeitas de que dispõem esses países o povo tem pouco poder, e o fundamental para os políticos que tomam as decisões no governo é a legitimidade da política econômica assegurada pelo apoio da sociedade civil.

Não é fácil convencer a sociedade civil dos países de renda média sobre a superioridade da macroeconomia do desenvolvimento em relação à macroeconomia convencional e do Novo Desenvolvimentismo sobre a ortodoxia liberal. Ideias novas demoram a se estabelecer. Nos anos 1990 a hegemonia ideológica do império foi quase 
absoluta, de forma que não havia espaço para alternativas teóricas ou práticas. Entretanto, o quadro mudou já no início dos anos 2000, quando começou a ficar evidente o fracasso do consenso de Washington em promover o desenvolvimento econômico e garantir a estabilidade financeira. Mudou definitivamente quando a crise financeira global mostrou que mesmo para os países ricos a receita de desregulação dos mercados era um grande equívoco. O mercado é uma maravilhosa instituição de coordenação de economias complexas, mas desde que devida e cuidadosamente regulados.

Hoje a ortodoxia liberal já não é mais hegemônica, mas a macroeconomia estruturalista do desenvolvimento e o Novo Desenvolvimentismo ainda não lograram substituí-la. Principalmente porque a macroeconomia estruturalista do desenvolvimento é constituída por um conjunto de modelos e o Novo Desenvolvimentismo, por um conjunto de propostas de política, que só se consolidaram do ponto de vista teórico recentemente. Mas já se avançou muito nessa direção, como ficou demonstrado quando 25 economistas e cientistas políticos de diversos países se reuniram em um workshop em São Paulo em maio de 2010, propuseram e aprovaram as "Dez Teses sobre o Novo Desenvolvimentismo" ("Ten Theses on New Developmentalism”). A esses economistas se juntaram 55 outros economistas e cientistas políticos importantes que foram convidados para serem também "subscritores originais" do documento. Essas "Ten Theses" podem ser vistas como uma alternativa concreta à macroeconomia neoclássica e ao consenso de Washington.

No processo de transição em curso do Novo Desenvolvimentismo para a condição hegemônica seus propositores enfrentam ainda uma questão colocada por seus interlocutores na sociedade civil. Eles dizem, "está bem, suas teorias e suas propostas fazem sentido, mas não é possível pô-las em prática, não é possível administrar a taxa de câmbio". Essa "impossibilidade" é, assim, o último bastião da ortodoxia liberal. Mas um bastião frágil. Seus defensores neoliberais dizem que na globalização é impossível estabelecer controles à entrada de capitais, mas a experiência histórica mostra que isto não é verdade. O Novo Desenvolvimentismo defende controles à entrada de capitais, não à sua saída, porque, como crises de balanço de pagamentos deixam de ser a "condição natural" dos países de renda média, não haverá razão para fugas de capitais. Por outro lado, embora haja problemas políticos internos em se estabelecer um imposto sobre as exportações de bens que dão origem à doença holandesa, está claro que isso é possível desde que fique claro que os exportadores não serão prejudicados, porque a depreciação cambial compensará o valor do imposto pago. Na verdade, os produtores de bens primários serão beneficiados desde que o governo use parte dos recursos para estabelecer um fundo de estabilização que os socorra nos casos de queda violenta dos preços internacionais da commodity. Finalmente, há duas dificuldades causadas temporariamente pelo deslocamento da taxa de câmbio do equilíbrio corrente para o in- 
dustrial: haverá um choque de custos que aumentará apenas uma vez a inflação, e os salários reais diminuirão um pouco. A inflação, porém, logo voltará a cair desde que não haja qualquer indexação de preços. Quanto aos salários, eles logo voltarão a subir, agora de forma sustentada, graças ao aumento da taxa de investimento e da aceleração do crescimento.

\section{REFERÊNCIAS}

BRESSER-PEREIRA, L. C. "Financiamento para o subdesenvolvimento: o Brasil e o segundo Consenso de Washington". In: CASTRO, A. C. (Org.). Desenvolvimento em debate: painéis do desenvolvimento brasileiro. Vol. 2. Rio de Janeiro: Mauad/BNDES: 2002, p. 359-398.

BRESSER-PEREIRA, L. C. Dutch disease and its neutralization: a Ricardian approach. Brazilian Journal of Political Economy, v. 28, n. 1, p. 47-71, January 2008.

BRESSER-PEREIRA, L. C. Globalização e competição. Rio de Janeiro: Elsevier, 2009.

BRESSER-PEREIRA, L. C.; GALA, P. Why foreign savings fail to cause growth. Revista de Economia Política, v. 27, n. 1, p. 3-19, 2007.

BRESSER-PEREIRA, L. C.; NAKANO, Y. Uma estratégia de desenvolvimento com estabilidade. Revista de Economia Política, v. 21, n. 3, p. 146-177, 2002.

BRESSER-PEREIRA, L. C.; NAKANO, Y. Economic growth with foreign savings? Brazilian Journal of Political Economy, v. 22, n. 2, p. 3-27, April 2003.

CHENERY, H. B.; BRUNO, M. Development alternatives in an open economy: The case of Israel. The Economic Journal, v. 72, n. 285, p. 79-103, March 1962.

EICHENGREEN, B. The real exchange rate and economic growth. San Francisco: UC Berkeley, 2008. Mimeo.

FLASSBECK, H. The exchange rate: economic policy tool or market price? UNCTAD Discussion Paper, n. 157, nov. 2001

GALA, P. Real exchange rate levels and economic development: theoretical analysis and econometric evidence. Cambridge Journal of Economics, v. 32, p. 273-288, March 2008.

HIRSCHMAN, A. O. “The rise and decline of development economics”. In: HIRSCHMAN, A. O. Essays in Trespassing: economics to politics and beyond. New York: Cambridge University Press, 1981[1979].

RAZIN, O.; COLLINS, S. M. Real exchange rate misalignments and growth. NBER Working Paper, n. 6174, September 1997. https://doi.org/10.3386/w6174.

RODRIK, D. The real exchange rate and economic growth: theory and evidence. Cambridge, MA: John F. Kennedy School of Government, Harvard University, July 2007. 